\title{
The effects of lesions to the rat hippocampus or rhinal cortex on olfactory and spatial memory: Retrograde and anterograde findings
}

\author{
KEVIN P. KAUT \\ University of Akron, Akron, Ohio \\ and \\ MICHAEL D. BUNSEY \\ Kent State University, Kent, Ohio
}

\begin{abstract}
The role of the hippocampal system in retrograde and anterograde amnesia was investigated by using a novel olfactory-guided paradigm and a traditional test of spatial learning. In the retrograde study, rats were trained on a sequence of two-choice olfactory discriminations in the weeks prior to receiving neurotoxic lesions of the hippocampus or aspiration lesions of the perirhinal-entorhinal cortex. Memory tests for preoperatively learned discriminations revealed no statistical impairment for subjects with damage to the hippocampus on a problem learned remote in time from surgery (i.e., 4 weeks +) or on the two recently learned discriminations (i.e., 1-3 weeks prior to surgery). The performance of subjects with perirhinal-entorhinal damage provided an important comparison for subjects with specific hippocampal lesions. Despite showing intact memory for the remotely learned problem, perirhinalentorhinal damage resulted in numerically (although not significantly) weaker performance on postoperative tests of retention for the discriminations learned in the 3 weeks prior to surgery. In the anterograde portion of the study, long-term memory for newly acquired discriminations was spared in subjects with damage to the hippocampus, whereas subjects in the perirhinal-entorhinal lesion group again showed the weakest memory performance on these tests of 5-day retention. Postoperative water maze learning was uniformly impaired in subjects with damage to the hippocampus and perirhinalentorhinal cortex, thus confirming the effect of these lesions and supporting the involvement of these brain areas in spatial processes. These findings further dissociate the specific involvement of the hippocampus in tasks of a spatial-relational nature versus nonrelational tasks, such as discrimination learning and recognition memory (e.g., Duva et al., 1997; Eichenbaum, 1997; Eichenbaum, Schoenbaum, Young, \& Bunsey, 1996). Moreover, the results suggest that damage to the hippocampus itself does not contribute to retrograde or anterograde memory impairments for all types of information, whereas the data suggest a more important role for the perirhinal-entorhinal cortex in recognition memory, irrespective of modality.
\end{abstract}

It has long been known that damage to the hippocampal system results in retrograde and anterograde amnesia (RA and AA) in both humans and nonhumans alike (Cho, Beracochea, \& Jaffard, 1993; Corkin, 1984; Corkin, Amaral, Gonzalez, Johnson, \& Hyman, 1997; Kim \& Fanselow, 1992; Reed \& Squire, 1998; Scoville \& Milner, 1957; Squire, 1992; Warrington \& McCarthy, 1988; Winocur, 1990; Zola-Morgan \& Squire, 1990; Zola-Morgan, Squire, \& Amaral, 1986). However, although the amnesic syndrome was initially attributed to damage to the hippocampus proper (i.e., dentate gyrus and areas CA3CA1), it is now clear that other components of the larger

We thank Art Belviso for his helpful assistance running subjects. This work is dedicated to the memory of Michael D. Bunsey. Correspondence concerning this article should be addressed to K. P. Kaut, Department of Psychology, University of Akron, 318F Polsky Building, 225 S. Main Street, Akron, OH 44325-4301 (e-mail: kpk@uakron. edu). hippocampal system-defined here as the hippocampus, the subiculum, the entorhinal cortex, and the perirhinal cortex (Eichenbaum, Schoenbaum, Young, \& Bunsey, 1996) - are implicated as well (Murray, 1996; Myhrer, 1992). In both humans and animal models, the brain damage underlying amnesia has generally been widespread, involving not only the hippocampus itself, but also other regions of the hippocampal system (e.g., RempelClower, Zola, Squire, \& Amaral, 1996; Zola-Morgan \& Squire, 1985; Zola-Morgan, Squire \& Mishkin, 1982; see also Murray, 1996), and in recent years it has become increasingly evident that severe memory deficits can follow damage restricted to these other hippocampal components (Meunier, Bachevalier, Mishkin, \& Murray, 1993; Meunier, Hadfield, Bachevalier, \& Murray, 1996; Murray, Gaffan, \& Mishkin, 1993; Otto \& Eichenbaum, 1992; Zola-Morgan, Squire, Amaral, \& Suzuki, 1989).

For example, performance of monkeys or rats in the delayed matching or nonmatching-to-sample tasks, 
which assess simple object or odor recognition and which are sometimes considered canonical tests of hippocampaldependent memory, is now thought to be critically dependent on the perirhinal and entorhinal cortices (PRER), rather than on the hippocampus proper (Meunier et al., 1993; Mumby, Wood, \& Pinel, 1992; Otto \& Eichenbaum, 1992; Suzuki, Zola-Morgan, Squire, \& Amaral, 1993; but see Alvarez, Zola-Morgan, \& Squire, 1995). Similarly, there is strong evidence that many forms of conditional or paired associate learning are more dependent on the PRER than on the hippocampus (Bunsey \& Eichenbaum, 1993; Jarrard, 1993; Murray et al., 1993). The opposite pattern of results obtains with certain other memory tasks. Most significant, in spatial learning situations, animals with specific damage to the hippocampus are consistently impaired, whereas-at least under certain conditions-lesions of the rhinal cortex may have little or no effect (e.g., Bouffard \& Jarrard, 1988; Holscher \& Schmidt, 1994; Jarrard, 1993; but see Liu \& Bilkey, 1998; Nagahara, Otto, \& Gallagher, 1995). Together, these results indicate that important functional subdivisions exist within the hippocampal system and may be manifest when lesions are restricted to specific subregions of the system (Gaffan \& Parker, 1996; Murray, 1996; Myhrer, 1992; Myhrer \& Johannesen, 1995).

Although this type of functional neuroanatomical approach has advanced our understanding of AA, it has not been as rigorously applied to the study of RA, despite a growing awareness that a clear conceptualization of hippocampal function requires a better understanding of RA (McClelland, McNaughton, \& O'Reilly, 1995; Nadel \& Moscovitch, 1997). Recent work has shown that RA can follow lesions of the perirhinal cortex (Eacott, 1998; Myhrer \& Wangen, 1996; Wiig, Cooper, \& Bear, 1996), the entorhinal cortex (Cho et al., 1993; Cho \& Kesner, 1996), and the PRER (Thornton, Rothblat, \& Murray, 1997), in addition to lesions of the hippocampus (Bolhuis, Stewart, \& Forrest, 1994; Kim, Clark, \& Thompson, 1995; Kim \& Fanselow, 1992; Salmon, Zola-Morgan, \& Squire, 1987; Winocur, 1990; Zola-Morgan \& Squire, 1990). However, few studies have directly compared the contribution of these different hippocampal components (but see Bolhuis et al., 1994; Wiig et al., 1996). Such comparisons may help clarify a source of confusion in the RA literature: Specifically, dramatic differences are reported in the extent of RA across studies, with gradients ranging from several days to months or years (e.g., Bolhuis et al., 1994; Salmon et al., 1987; Winocur, 1990; Zola-Morgan \& Squire, 1990). Perhaps these different RA gradients in part reflect varying degrees of damage to particular hippocampal system components (e.g., RempelClower et al., 1996).

The present study addressed the functional neuroanatomy of RA, comparing the effects of lesions to two components of the hippocampal system-the hippocampus and the PRER - on memory of simple olfactory information. At least two patterns of results are possible in this situation. First, it is conceivable that the two lesions would result in comparable degrees of RA. Although simple discriminations of the type used here exemplify socalled nonrelational processing and are often spared when learning occurs after hippocampal lesions (Cohen \& Eichenbaum, 1993; Eichenbaum, Otto, \& Cohen, 1992; Vnek \& Rothblat, 1996), the results may differ when learning precedes surgery. The one existing study directly comparing the retrograde effects of hippocampal and rhinal cortex lesions supports this possibility. Wiig et al. (1996) showed that lesions of the perirhinal cortex, the fornix, or the perirhinal cortex + the fornix all caused a graded RA of similar magnitude for visual discriminations. These results suggest that the hippocampal system may act as a functional unit in memory consolidationeven for nonrelational information. However, although fornix lesions are generally considered hippocampal lesions in that they deprive the hippocampus of neuromodulatory inputs, these lesions also disrupt the entorhinal cortex (Mitchell, Rawlins, Steward, \& Olton, 1982), and this entorhinal disruption may contribute to the observed RA (see Myhrer, 1992).

A second, very different prediction also seems reasonable - that is, that only a lesion targeting the PRER will compromise simple olfactory memories acquired prior to damage. This prediction follows from the straightforward reasoning that lesions of the hippocampus do not disrupt postoperative acquisition of discrimination learning (Vnek \& Rothblat, 1996; Zola-Morgan et al., 1982). Given the recent studies implicating the perirhinal and/or the entorhinal cortex in retrograde and anterograde recognition memory (e.g., Cho et al., 1993; Cho \& Kesner, 1996; Myhrer, 1992; Myhrer \& Johannesen, 1995; Thornton et al., 1997), it is tenable that only damage including the rhinal cortex will interfere with memories formed prior to a lesion. Furthermore, inasmuch as the hippocampus is largely uninvolved in the processing of such nonrelational information, we may thus expect it to have no significant role in the consolidation of simple discriminations.

Finally, negative results following both hippocampal and PRER damage might also be anticipated if these brain regions have no role in memory consolidation for the type of information used here. Studies that have shown RA following hippocampal system lesions have traditionally employed tasks emphasizing contextual fear conditioning or visual recognition memory (e.g., Anagnostaris, Maren, \& Fanselow, 1999; Kim \& Fanselow, 1992; Thornton et al., 1997; Wiig et al., 1996; ZolaMorgan \& Squire, 1990). A lack of RA for olfactory information here might suggest modality-related differences in hippocampal-dependent memory processing and would be consistent with results from other studies using olfactory cues (e.g., Staubli, Fraser, Kessler, \& Lynch, 1986).

In the present study, rats were trained on a series of simple olfactory discriminations prior to lesions of the hippocampus or the rhinal cortex, and retention was assessed following recovery. Importantly, lesions of the 
hippocampus were effected using ibotenic acid, a selective neurotoxin that destroys cell bodies while sparing axons and neighboring brain areas (Jarrard, 1989). This lesion approach allows us to more conclusively attribute any resulting RA to damage to the hippocampus itself. Rhinal cortex lesions were performed using an aspiration technique. Although this technique is less selective and often causes damage to portions of the hippocampus, this was not a substantive concern in the present study. The primary aim of this study was to assess the contribution of the hippocampus itself to RA; as a first step, we wanted to compare the effects of specific hippocampal lesions with the RA-inducing effects of larger lesions to the hippocampal system (e.g., the hippocampus plus the rhinal cortex).

The design used here is similar to that used in previous RA studies (Salmon et al., 1987; Wiig et al., 1996) and involves a rapidly acquired olfactory task developed in this lab (Bunsey \& Eichenbaum, 1996). A minimum number of trials are required during training, and retention can be assessed in a single probe trial, thereby providing a measure of memory in the absence of relearning.

Following the RA testing for olfactory learning, the subjects were tested in a single-day version of the water maze (Kraemer, Brown, Baldwin, \& Scheff, 1996) and in the long-term retention of postoperatively acquired olfactory discriminations. Deficits were expected in water maze performance in hippocampal and PRER subjects, thereby allowing us to rule out inadequate lesions in the case of negative results in the RA test. No deficit was expected in the retention of postoperatively acquired discriminations for hippocampal subjects, whereas PRER subjects were expected to show weaker long-term memory for new olfactory learning (Flint, Kaut, \& Bunsey, 1997).

\section{METHOD}

\section{Subjects}

Thirty male Long-Evans rats (Charles River supplier), weighing approximately $300-400 \mathrm{~g}$ at the start of the experiment, were used as subjects. They were maintained on a 15:9-h light:dark cycle (lights on at $0700 \mathrm{~h}$ ) and were housed individually in clear plastic home cages $(47.3 \times 23.3 \times 20 \mathrm{~cm})$. Home cages were lined to a depth of $\sim 2 \mathrm{~cm}$ with rodent bedding and were fitted with wire cage tops to allow delivery of food and water. Throughout training and testing, the subjects had unlimited access to water and were kept on a mild food-deprivation schedule (i.e., 20-25 g rodent chow per day). All training and testing occurred in the home cage.

\section{Behavioral Training}

Olfactory discriminations. The subjects were initially trained to dig through sand-filled plastic cups to obtain buried cereal rewards. The cups (Nalgene Manufacturers, $6.4 \times 6.3 \mathrm{~cm}$ ) were affixed with Velcro to an opaque Plexiglas base $(20 \times 11 \times 3 \mathrm{~cm})$ and were filled with approximately $150 \mathrm{~g}$ of sand. Unscented sand was used during shaping and was then scented with various odors for discrimination training and testing.

Shaping. The first 2 days of shaping were conducted in the animal vivarium. On Day 1, a single cup mounted on a Plexiglas base was filled with unscented sand and placed at the front of each rat's home cage. The cup remained in the home cage for two 1-h trials, separated by a $1-\mathrm{h}$ interval. On these shaping trials, the cup contained 12 half-pieces of sweetened cereal (e.g., Froot Loops or Fruit Rings) buried accordingly: Four pieces were completely buried, 4 were partially buried, and 4 were placed on the sand surface. At the end of each trial, the experimenter removed the cup and counted the number of pieces retrieved. Those subjects not consistently retrieving rewards were given a third trial on this day. On Day 2, a pair of cups were mounted on a Plexiglas base (separated by $3 \mathrm{~cm}$ ) and placed in the home cage. Only one cup contained cereal rewards. On the first of two 10-min trials, some of the rewards were buried, and others were exposed; on the second trial, all the rewards were buried. The left and the right cups were each baited once on Day 2 .

On Day 3 and all subsequent days, training occurred in a welllighted experimental room separate from the animal vivarium. The subjects were given six trials on each of these shaping days. For each trial, two unscented sand-filled cups, only one of which contained rewards, were placed at the front of the home cage. On the first trial of Day 3, four to six cereal pieces were placed in the reward cup, some of which were left exposed on the surface to encourage digging. On later trials, all the rewards were buried to a depth of approximately $2.5 \mathrm{~cm}$ below the surface. The subjects were given unlimited time to retrieve a minimum of two rewards. Shaping procedures continued for 3-5 more days (six trials per day) until all the subjects were rapidly and consistently retrieving two buried rewards.

Discrimination training. Following the shaping procedures, the rats were then trained on a series of simple olfactory discriminations. For these discriminations, the sand was scented by mixing one of the following odors according to a percentage of total weight: coffee $(1 \%)$, allspice $(0.5 \%)$, cocoa $(1 \%)$, garlic $(1 \%)$, cinnamon $(1 \%)$, clove $(0.6 \%)$, onion $(1 \%)$, marjoram $(1 \%)$, thyme $(1 \%)$, sage $(1 \%)$, cumin $(1 \%)$, and turmeric $(1 \%)$. Each discrimination consisted of a pair of these odors-for example, cocoa and garlic-one of which served as the S+, or baited, odor and one as the $\mathrm{S}-$. Reward odor for each discrimination was counterbalanced across subjects (with the exception of Discrimination 1), and each rat was assigned to one of two sequences of discrimination training, thus precluding any effect of presentation order on performance. In addition, the placement of the reward cup (i.e., right or left position on the Plexiglas base) was randomized across all training and testing trials.

Figure 1 provides a description of the retrograde training and testing procedures and includes a schematic representation of the rodent digging task. On the first discrimination problem in the training sequence, the subjects received 10 trials per day for 2-3 days to ensure that all the subjects had mastered the procedural aspects of the task (e.g., readily approaching the cups, digging through scented sand) and were exposed to differentially scented sand-filled cups as part of the discrimination paradigm. On each trial, a pair of scented cups, one of which $(\mathrm{S}+)$ was baited with four buried rewards, was placed at the front of the home cage. The cups remained there until the subject retrieved two rewards from the S+ cup (i.e., a correction procedure was used), which allowed the subjects to forage through one or both cups, thereby reinforcing the association between odor and reward value $(\mathrm{S}+=$ coffee, $\mathrm{S}-=$ allspice $)$ regardless of the first-choice accuracy per trial. Following retrieval of the second reward, the cups were removed, and an intertrial interval of approximately 2-4 min was observed, during which time other subjects were trained accordingly.

One to 2 days after the completion of Problem 1, the subjects were trained on a sequence of five discriminations (Problems 2-6), each consisting of a unique pair of odors (see Figure 1). Each discrimination problem involved 1 week of training, and a 3-day interval was observed between problems. For each problem, the subjects received a total of 12 training trials distributed according to the following format: 8 trials on Day 1 (of that problem), 2 trials on Day 3, 


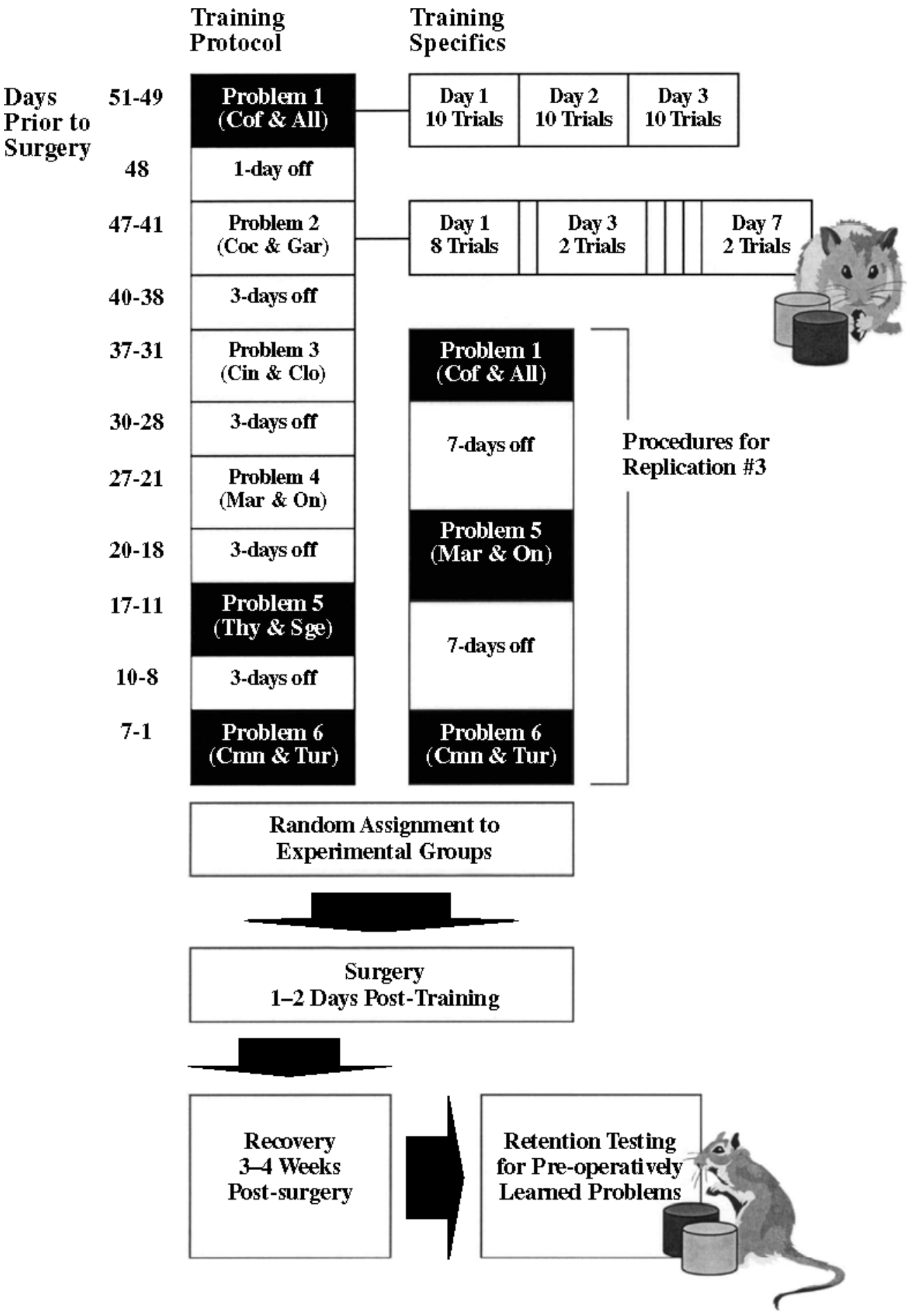

Figure 1. Training and surgery protocol for retrograde study. The discrimination problems used for purposes of statistical analysis are indicated in black boxes. The training specifics indicated for Problem 2 (i.e., training trials on Days 1, 3, and 7) were also followed for Problems 3-6. Note that the procedures for the subjects in Replication 3 were modified. Problem 1 for these subjects was presented 31 days prior to surgery; however, the critical recent discriminations (also referred to as Problems 5 and 6 for subjects in Replication 3) were presented in the 3 weeks prior to surgery for all the replications in this study. Cof, coffee; All, allspice; Cin, cinnamon; Clo, clove; Gar, garlic; Coc, cocoa; Mar, marjoram; On, onion; Thy, thyme; Sge, sage; Cmn, cumin; and Tur, turmeric. Note: The presentation order for the odor pairs in Problems 2-5 was reversed for half of the subjects in the first two replications. 
and 2 trials on Day 7. For each of these training trials, the initial cup choice was recorded (i.e., designated as the cup where a rat's nose or paw first contacted the sand), allowing us to calculate a percentage correct index for each subject during acquisition. Five subjects in the first replication of this study inadvertently received fewer training trials per problem (e.g., 8 trials rather than 12). One of these subjects was later assigned to the hippocampal lesion group, 1 to the PRER surgery group, and three served as unoperated controls.

Pilot work in this lab had shown that the spacing of trials over a 1 -week period resulted in robust retention after minimal training. However, following the first two replications of this experiment, we found unreliable levels of retention for the discriminations in the middle of the training sequence (i.e., Pairs 2, 3, and 4), possibly owing to interference caused by the combination of the large number of discriminations and the small number of training trials. Consequently, the subjects in the last of three replications $(n=7)$ were trained using the first discrimination (i.e., coffee and allspice, 3 days of 10 trials) and, following a 1-week interval, were trained on two discriminations (referred to as Problems 5 and 6), separated by a 1-week interval (see Figure 1). This altered training protocol was associated with a slight increase in the percentage of correct first cup selections for these subjects on recent $(M=78 \%)$ and remote $(M=83 \%)$ problems during training compared with subjects from the first two replications (recent $M=67 \%$, remote $M=76 \%$ ). The most notable difference was evident for control subjects from the third replication $(n=3)$, who showed better first cup selection on the two recent problems $(M=92 \%)$ than did control subjects from earlier replications $(n=7 ; M=67 \%)$. Despite these differences in first-choice accuracy, training performance was uniformly above chance on the remote and recent problems across all training groups (Replications 1 and 2, $M=71 \%$; Replication 3, $M=81 \%$ ).

It is important to note that the first-choice measure is not considered the most reliable index of learning on this task. Indeed, the use of the correction procedure here ensured that all the subjects had to forage through the $S+$ cup on each trial in order to retrieve rewards, regardless of initial cup selection. In this way, the opportunity to form an association between food reward and olfactory cues was similar for all the subjects on each trial (i.e., retrieve two buried rewards from the $\mathrm{S}+$ cup) regardless of any strategy that may have resulted in poor first-choice selection at any time during training (e.g., win-stay-lose-shift; side preference; see the Retention Testing and Results sections, below).

For purposes of statistical analysis, only the data from Problem 1 (i.e., remote problem) and Problems 5 and 6 (i.e., two recent problems), which were common to all subjects, were considered. Most important, the use of Problems 5 and 6 provided a reliable index of memory for discriminations learned within 3 weeks of surgery (i.e., recent learning), and Problem 1 allowed us to separately examine retention performance on a discrimination learned at least 4 weeks prior to surgery, a remote time period that is consistent with previous studies and mathematical models of hippocampal-dependent consolidation parameters in rodents (e.g., Kim et al., 1995; Kim \& Fanselow, 1992; McClelland et al., 1995).

One to 2 days following the final day of training on the last problem, the subjects were randomly assigned to treatment or control groups, and surgery was performed.

\section{Surgical Procedures}

The subjects were randomly assigned to groups that received no surgery or sham surgery (group CON), hippocampal lesions (group HIPP), or PRER lesions (group PRER). The subjects undergoing surgery were anesthetized with Nembutal $(65 \mathrm{mg} / \mathrm{kg})$ and received additional injections of Nembutal $(0.05 \mathrm{ml})$ or an inhalant (i.e., Metofane for $\sim 30 \mathrm{sec}$ ) to maintain a surgical plane of anesthesia throughout surgery. Lesions of the hippocampus were conducted according to the procedures developed by Jarrard (1989). Briefly, the subjects were placed in a stereotaxic apparatus (Stoelting) with the incisor bar set at $3.5 \mathrm{~mm}$ below zero. Following a midline incision, the scalp was reflected and secured with hemostats, and the skull overlying the injection field was removed with a precision drill. Ibotenic acid (Sigma, $10 \mathrm{mg} / \mathrm{ml}$ ) dissolved in physiological saline $(\mathrm{pH} 7)$ was injected using a 10-ml Hamilton syringe. Injections of $0.05-0.25 \mu \mathrm{l}$ were made over a $30-60 \mathrm{sec}$ delivery period at 14 sites bilaterally throughout the dorsal and ventral extent of the hippocampus. Sham surgeries were similar to ibotenic acid surgeries, except that the syringe was not lowered into the brain. Following surgery, the incision was sutured, and the subjects were returned to their home cages for recovery.

PRER aspirations were conducted using an adjustable head holder that allowed for movement of the head in the medial-lateral plane. Once secured in the apparatus, a midline incision was made, and the scalp, fascia, and underlying temporal muscle were reflected, exposing the temporal bone and zygomatic process. A small portion of temporal bone was then removed using a precision drill. The PRER aspiration was conducted under visual guidance with the aid of a dissecting microscope. The rhinal cortices were removed bilaterally with a 20 -gauge needle attached to a vacuum pump providing gentle suction pressure. Gel foam was placed in the skull where drilling had occurred, and the scalp was sutured.

The subjects were given a recovery period of 3-4 weeks. During this time, rodent chow was provided ad lib for the 1 st week, followed by a return to a mild food-deprivation regimen prior to the start of retention testing for preoperatively learned discriminations.

\section{Retention Testing}

Retention testing was conducted following complete recovery from surgery. On the 1st day of testing, the subjects were given six trials of the first, or remote, problem, the first trial of which was an unbaited probe trial. On this probe trial (and all subsequent probes), no rewards were buried in the S+ cup, and the amount of time spent digging in each of the cups was recorded. The rats were allowed to forage through the cups until one of two discontinue criteria had been met: (1) $10 \mathrm{sec}$ of total digging (both cups combined) or (2) a period of 10 consecutive seconds of nondigging. At this point, a cereal reward was dropped onto the surface of the designated S+ cup, and the cups were removed once the subject had retrieved the reward. Retention testing for the remaining problems occurred over the next 1-2 days. Recent and remote problems were presented in an intermixed fashion. The first presentation of each problem at retention testing was an unbaited probe trial, interleaved with baited trials from previous problems that had already been probed. This interleaved presentation of baited trials during probe testing was designed to maintain a good level of digging persistence throughout the period of retrograde testing.

All the probe trials were videotaped using an RCA video recorder mounted on a tripod and positioned approximately $3 \mathrm{~m}$ from the front of the home cage. These videotapes were later reviewed to ensure accuracy in reporting the amount of time spent digging in the cups for each probe trial. The relative amount of time spent digging in the correct cup $(\mathrm{S}+)$ was used as the dependent measure of retention. Specifically, a d' or preference index was calculated according to the formula $(x-y) \div(x+y)$, where $x=$ seconds digging in the $\mathrm{S}+$ cup and $y=$ seconds digging in the $\mathrm{S}-$ cup. The unbaited probe procedure allowed us to measure retention in the absence of relearning and ensured that good performance was not being guided by direct detection of the reward. Furthermore, probe trials of this type yield additional information not offered by standard discrimination paradigms limited to measures of initial choice accuracy. In the digging task used here, initial choice data can occasionally reflect behavioral artifacts ranging from impulsive responding and/or the brief sampling of an odor to a persistent side preference (e.g., right or left cup) early in acquisition training. Accordingly, the choice measure alone in this task provides one level of information regarding learning, but the preference index, predi- 
cated on a rat's digging persistence, is believed to offer a more reliable indicator of memory for reward odor. A preference index score of +1.00 reflects perfect preference for the $\mathrm{S}+$ odor, whereas an index score of -1.00 indicates a complete and incorrect preference for the $\mathrm{S}-$ odor. A preference index of 0.00 reflects chance performance on these probe measures.

For purposes of statistical analysis, only those subjects producing digging times of $1 \mathrm{sec}$ or greater per probe trial were included in the planned analyses of variance (ANOVAs; i.e., one remote and two recent problems per subject). This conservative criterion was established to ensure a reliable index of memory.

\section{Postoperative Learning}

After retrograde testing was complete, a large subset of the animals was tested on two new odor discriminations and on a singleday version of the water maze. Training on this postoperative phase of the experiment began a minimum of 60 days after the subjects had completed the probe testing for the retrograde portion of the study. One animal from each lesion group developed health problems just prior to the anterograde olfactory test, and the data from these subjects were dropped from the anterograde portion of the study.

Olfactory training involved two new odor pairs (i.e., cardamom $[1 \%]$ and anise $[1 \%]$; coriander [1\%] and fenugreek $[1 \%])$. The procedures were similar to those used for retrograde training, except that the subjects received four trials on Day 1 of each discrimination and two trials on Day 2 and were tested with a probe measure on the first trial of Day 7. The subjects were trained and tested on each discrimination pair consecutively, with an interval of 5-7 days of no training between the retention probe test for the first pair and the start of training for the second pair. The probe measures were videotaped as described previously, and the tapes were later reviewed to obtain accurate digging times for preference index calculation.

The subjects were also trained on a single-day version of the water maze according to the procedures established by Kraemer et al. (1996). The maze used here was a circular metal tank, measuring $1.2 \mathrm{~m}$ in diameter and $0.6 \mathrm{~m}$ high. Water maintained at room temperature filled the tank to a level approximately $19 \mathrm{~cm}$ below the rim. The escape platform, a square black plastic base $(14 \times 15 \mathrm{~cm})$, was located roughly in the center of the northeast quadrant and was submerged $2 \mathrm{~cm}$ below the water surface. The maze tank was located in a room with distinctive geometric shapes and object patterns affixed to the north, east, and west walls. Two 40-W lamps were positioned on the floor near the northwest and southwest corners to illuminate the west well, thus adding a light gradient to the room. A video camera (RCA camcorder) mounted on a tripod was secured to a table approximately $0.3 \mathrm{~m}$ from the south starting point of the maze, with the camera fixed at a height of $1.98 \mathrm{~m}$ above the rim of the maze tank. The experimenter remained seated throughout training at a position approximately $0.6 \mathrm{~m}$ from the south quadrant of the maze.

The training procedure used here involved three blocks of four trials, with a 1-h interval observed between blocks of training. During these intervals, the rats were removed from the maze room, thoroughly dried, and returned to their home cages, and were placed in a room located next to the maze room. During each block of training, the rats were started once from each of four start locations $(\mathrm{N}, \mathrm{S}, \mathrm{E}$, and $\mathrm{W})$. The order of start locations was pseudorandomized across blocks. On each trial, the rats were placed into the water at one of the start locations and given a maximum of $90 \mathrm{sec}$ to locate the submerged platform. Latency to find the platform was recorded for each trial. The subjects were to remain on the platform for a total of $20 \mathrm{sec}$, and were then removed and returned to a home cage situated on the floor next to the south wall in the maze room. Those subjects not reaching the platform in $90 \mathrm{sec}$ were guided to the platform manually. Those subjects leaving the platform prior to the 20 -sec requirement were returned manually until the time limit had been met.

Immediately following the last trial of training (i.e., Block 3, Trial 4), the escape platform was removed, and the subjects were started from the south location for a 90 -sec videotaped probe trial. These tapes were later reviewed and scored for measures of time spent in the target quadrant and number of platform crossings.

\section{Histology}

Following behavioral testing, the subjects were euthanized with an overdose of Nembutal (i.e., $1 \mathrm{ml}$ i.p. injection, $50 \mathrm{mg} / \mathrm{ml}$ ) and were perfused with physiological saline and a $10 \%$ formalin solution. The brains were removed and placed for several days in a formalin and sucrose solution. The brains were then embedded in gelatin (Sigma: bovine, type B) and were returned to a $10 \%$ formalin solution until slicing. The brains were sliced at a thickness of $60 \mu \mathrm{m}$, using a freezing microtome. Every fourth slice was then slide-mounted, stained with cresyl-violet, and cover-slipped for later analysis.

Lesions for each subject in groups HIPP and PRER were reconstructed from the stained sections and sketched onto a series of five coronal plates selected from the atlas of Pellegrino, Pellegrino, and Cushman (1979; i.e., from Bregma -1.4, -2.4, -3.6, -4.2, and $-5.0 \mathrm{~mm})$. A lesion template consisting of gridded squares $(2 \times 2$ $\mathrm{mm}$ ) covering the region of the hippocampus (dentate gyrus, areas CA3-CA1), and a grid of small diameter circles $(\sim 1 \mathrm{~mm}$ diameter and $\sim 2 \mathrm{~mm}$ separation between circles) marking the PRER was developed for each of these coronal sections for the purpose of identifying and recording areas of tissue damage in each group. A transparency of each lesion template was then laid over the corresponding sketch plates for each subject, and the amount of tissue damage was counted for each coronal plate. Representations of a largest and smallest lesion for groups HIPP and PRER were then reconstructed onto coronal plates from the atlas of Paxinos and Watson (1997).

\section{RESULTS}

\section{Histology}

Histological analysis of hippocampal lesions revealed a general pattern of substantial damage throughout the hippocampus. Quantification of lesion size showed that damage to the hippocampus proper ranged from $22 \%$ to $83 \%$ in these subjects, with an average of 57\% tissue destruction (dentate gyrus, CA3-CA1). Figure 2A represents the pattern of damage in subjects with one of the largest and one of the smallest lesions in group HIPP; the average amount of damage to the hippocampus at each of five coronal plates (a-e) is provided in Figure 2B. It is apparent that extensive damage was frequently observed to the anterior-most portions of the dorsal hippocampus, although the subject with the smallest lesion showed considerable sparing to this region of the hippocampus (Figure 2A, coronal plate a). However, substantial tissue destruction or disruption of the normal cytoarchitecture was evident for the majority of animals in midseptotemporal hippocampal subfields (i.e., mean tissue damage of $50 \%-60 \%$ ), even in the smallest lesion. Despite substantial disruption to the hippocampus in the majority of these subjects, sparing was evident in the caudal extension of the hippocampus, where mean tissue damage was less than $30 \%$. The inset in Figure 2B illustrates the variability in lesion size to the caudal portions 
A

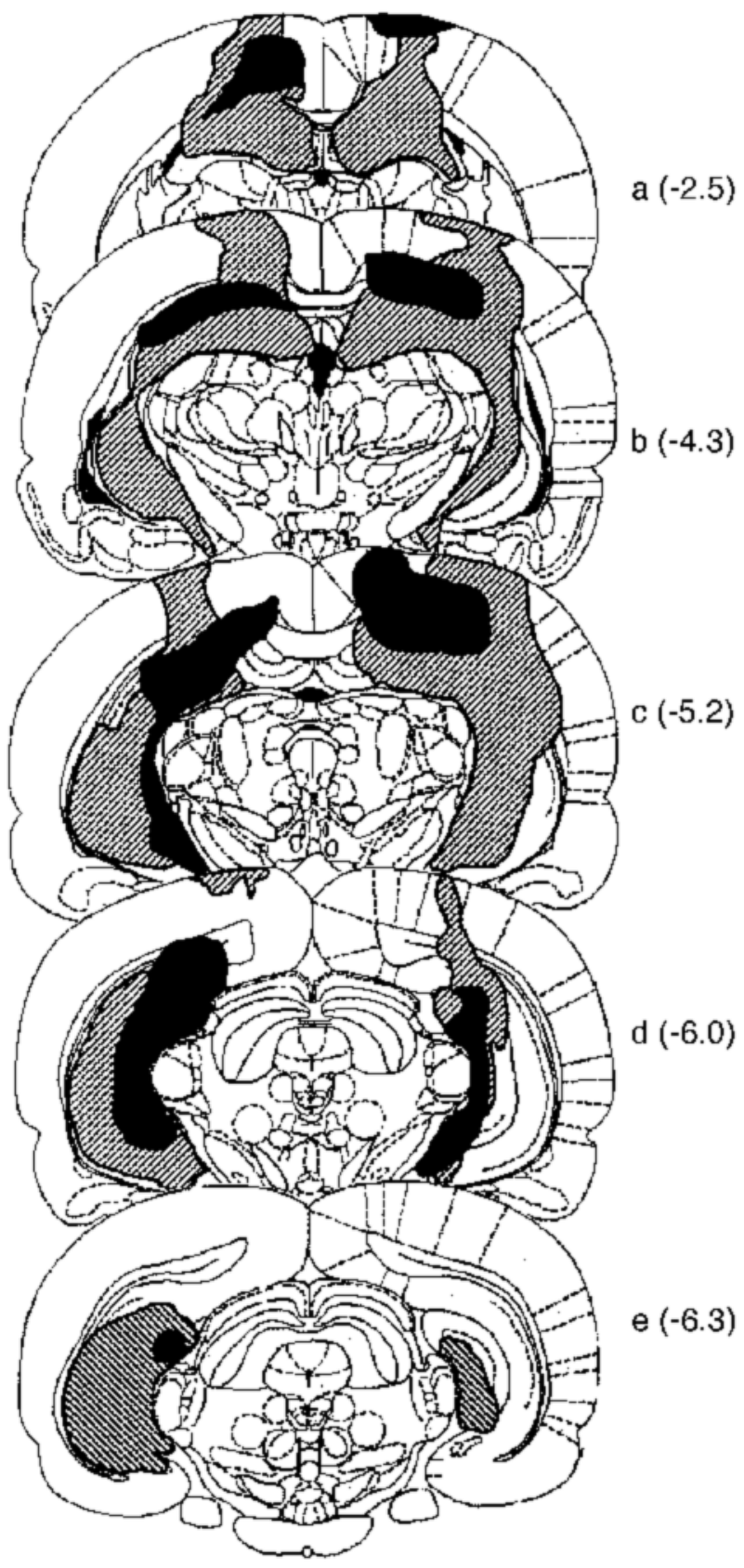

B

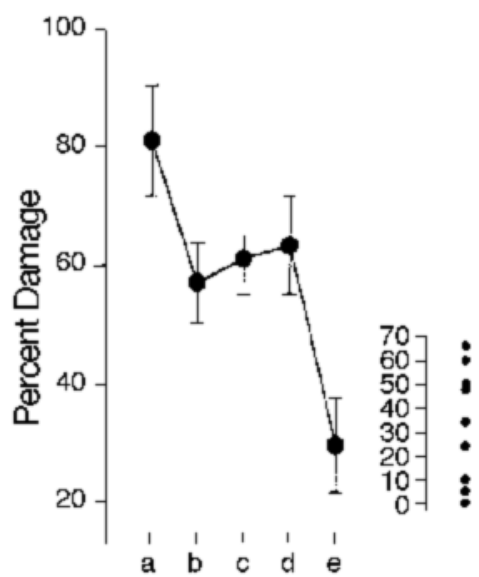

Coronal Sections

Figure 2. Analysis of lesions to the hippocampus (HIPP). (A). Reconstructions of a large (line-fill) and the smallest (dark fill) lesion at five coronal sections in Group HIPP. (B). Average amount of damage to the hippocampus at each of five coronal sections for all the subjects in group HIPP. Coronal sections (a-e) correspond to the lesion plates represented in panel A. The inset in panel B illustrates the variability evident in the amount of tissue damage to one caudal portion of the hippocampus corresponding to coronal plate e (i.e., the plate showing the most overall sparing in this lesion group).

of the hippocampus (coronal plate e; range of damage, $0 \%-66 \%$ ), reflecting an average of $29 \%$ tissue damage overall, with a number of subjects $(n=5)$ showing less than $25 \%$ damage. Tissue sparing was also evident in select subjects to the anterior portions of the temporal hippocampal extension (see Figure 2A, coronal plate b). Cortical damage was frequently observed in these sub- jects, especially to portions of the parietal cortex overlying the dorsal hippocampus.

The subjects in group PRER presented substantial damage to PRER. Figure 3A presents the largest and the smallest lesions in this group and indicates that ancillary damage was also noted to the amygdala and portions of the temporal neocortex. These rhinal cortex ablations 


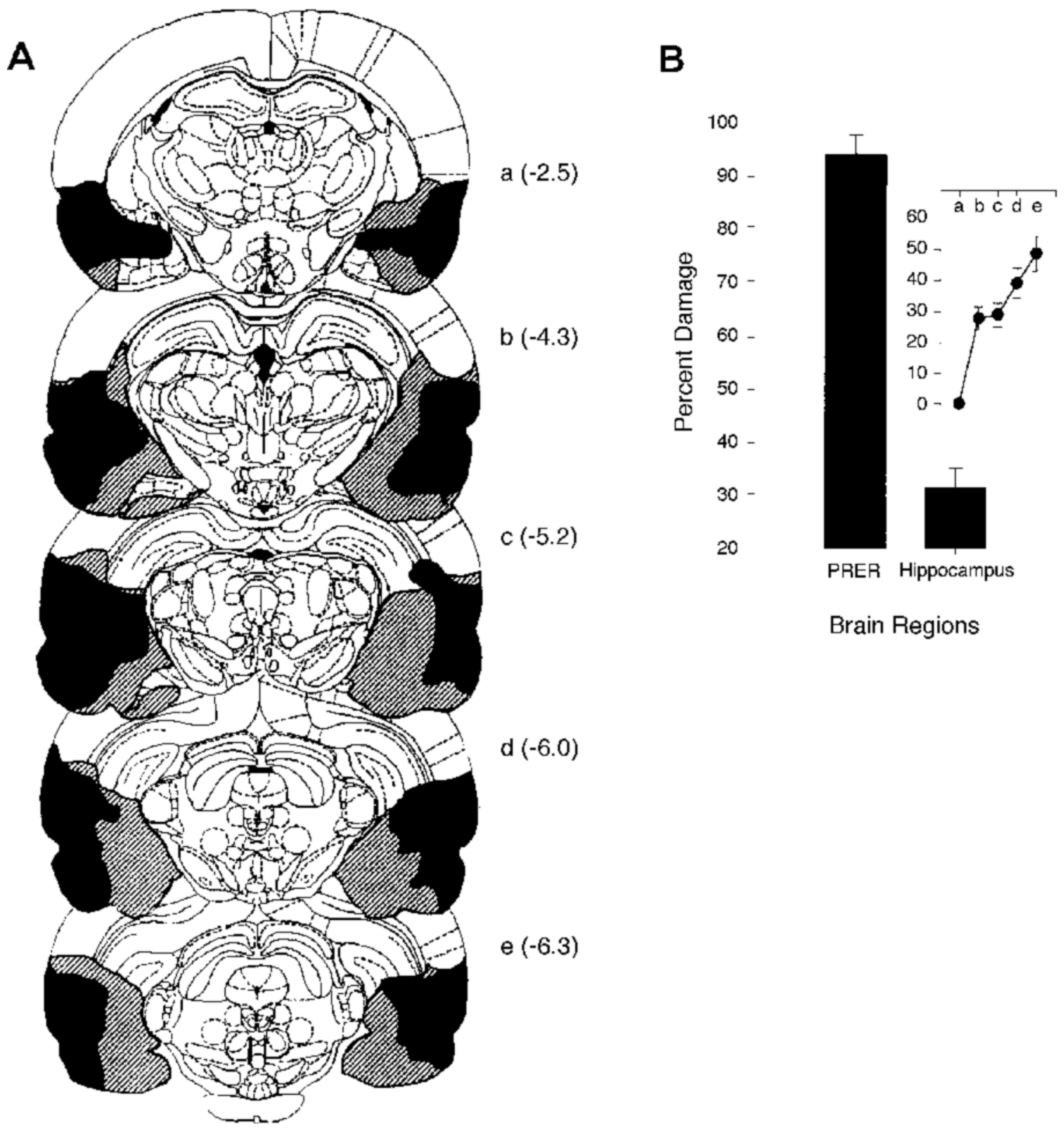

Figure 3. Analysis of lesions to the perirhinal-entorhinal cortex (PRER). (A) Reconstructions of the largest (linefill) and smallest (dark-fill) lesions at five coronal sections in Group PRER. (B) Representation of the average amount of damage to the rhinal cortex in Group PRER and the average amount of incidental damage involving the hippocampus in these subjects. The inset in panel $B$ illustrates the average amount of specific hippocampal damage evident for the subjects in Group PRER at each of the five coronal plates (a-e) represented in panel A.

also encroached upon hippocampal subfields (generally ventral components) and the subiculum, with destruction to the hippocampus ranging from $18 \%$ to $45 \%$ (i.e., $M=$ $31 \%$ damage). Figure 3B illustrates the near complete ablation of the rhinal cortex in this group (i.e., $M=90 \%$ ) and reflects the modest amount of damage to the hippocampus. Specifically, reference to the inset of Figure 3B reflects the average amount of damage to the hippocampus in group PRER at each of the five coronal sections used in the lesion analysis. The lesion for 1 subject in group PRER was not subjected to quantitative analysis owing to poorly stained tissue. However, inspection of the gross lesion confirmed the presence of substantial damage to regions of the PRER, with additional destruction noted to portions of the temporal neocortex and the ventral hippocampus. Overall, there was no damage evident to the rostral portions of the dorsal hippocampus in group PRER, whereas lesion size increased in the cau- 
dal and temporal extent of the hippocampus, with the majority of damage noted for portions of the ventral hippocampus.

\section{Retrograde Olfactory Discriminations}

The percentage of correct first cup selections for all the subjects on Problem 1 and Problems 5 and 6 during the preoperative training phase is presented in Figure 4. It is important to note that on this task, where relatively few training trials are used, the percentage correct firstchoice score is not considered a critical index of learning. The use of the correction procedure here ensured that the rats had to dig through the $\mathrm{S}+$ odor on each trial in order to retrieve buried rewards. In this way, regardless of first-choice accuracy per trial, the subjects were given the opportunity to associate reward odor with food. Complete percentage correct scores were unavailable for 4 subjects $(\mathrm{CON}=1, \mathrm{HIPP}=1$, PRER $=2)$, and the acquisition scores were therefore based on the remaining majority $(\mathrm{CON}=10, \mathrm{HIPP}=9, \mathrm{PRER}=7)$. Overall performance was at a level above chance during acquisition of these discriminations, and no differences were evident between groups on the critical recent discrimination problems $[F(2,23)=1.081, p=.356]$. Performance on the remote problem during training was not as uniform across subjects, where a group difference $[F(2,23)=$ $5.529, p=.011]$ reflected fewer initially correct choices for subjects later assigned to group PRER than for those placed in groups CON and HIPP (Tukey post hoc tests, both $p$ s <.05). Despite a lower first-choice percentage on Problem 1 during acquisition training, group PRER demonstrated excellent preference index scores for this problem on the postoperative retention test (see below). The subjects selected for groups CON and HIPP did not differ from each other in their first-choice accuracy on the remote problem (Tukey post hoc test, $p=.909$ ), thus presenting a comparable learning profile throughout training.

The mean preference index scores on the postoperative memory test for Problem 1 are presented in Figure 5. Following the removal of data for those subjects failing to achieve the minimum standard of 1-sec total digging on the probe trial, the following group sizes were used in this analysis: CON, $n=10$; PRER, $n=8$; and HIPP, $n=9$. A one-way ANOVA (group $\times$ problem) failed to detect a significant difference among groups on this probe test $[F(2,24)=0.530, p=.595]$. Although first-choice accuracy for group PRER on this problem during preoperative training was weaker than that for groups CON and HIPP (see Figure 4), their memory for this remotely learned problem at the postoperative probe test strongly suggests a well-established association between reward valence and individual odor (i.e., $\mathrm{S}+=$ coffee, $S-=$ allspice). Indeed, the subjects in group PRER $(M=0.722)$ showed a stronger numerical performance on this problem than did the subjects in group CON $(M=0.558)$ or group HIPP $(M=0.483)$. This underscores our belief that the correction procedure used during preoperative training facilitates the establishment of reward-odor associations, even though first-choice accuracy on each trial may not necessarily reflect such learning. Ultimately, the digging time measure taken at

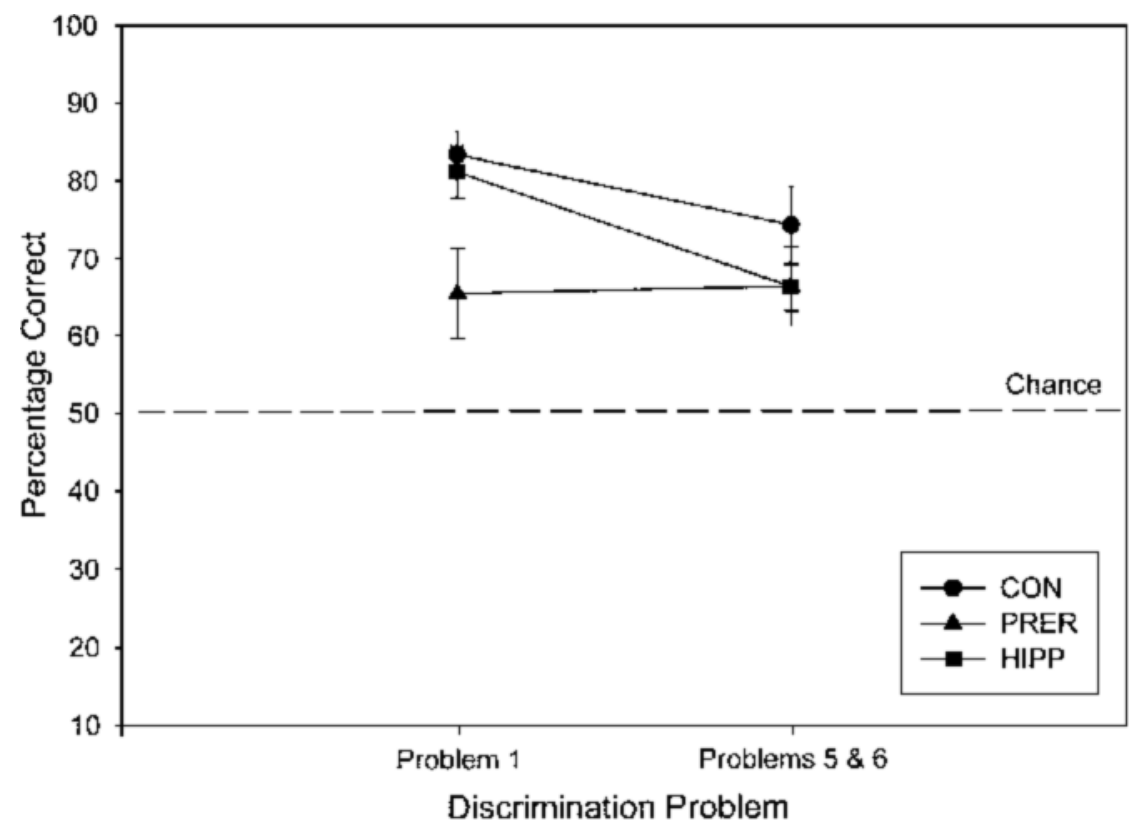

Figure 4. Mean percentage of correct first choices $( \pm S E M)$ for control $(\mathrm{CON})$, perirhinalentorhinal (PRER), and hippocampal (HIPP) subjects on Problem 1 and Problems 5 and 6 (i.e., the two recent problems) during presurgery training (acquisition). 


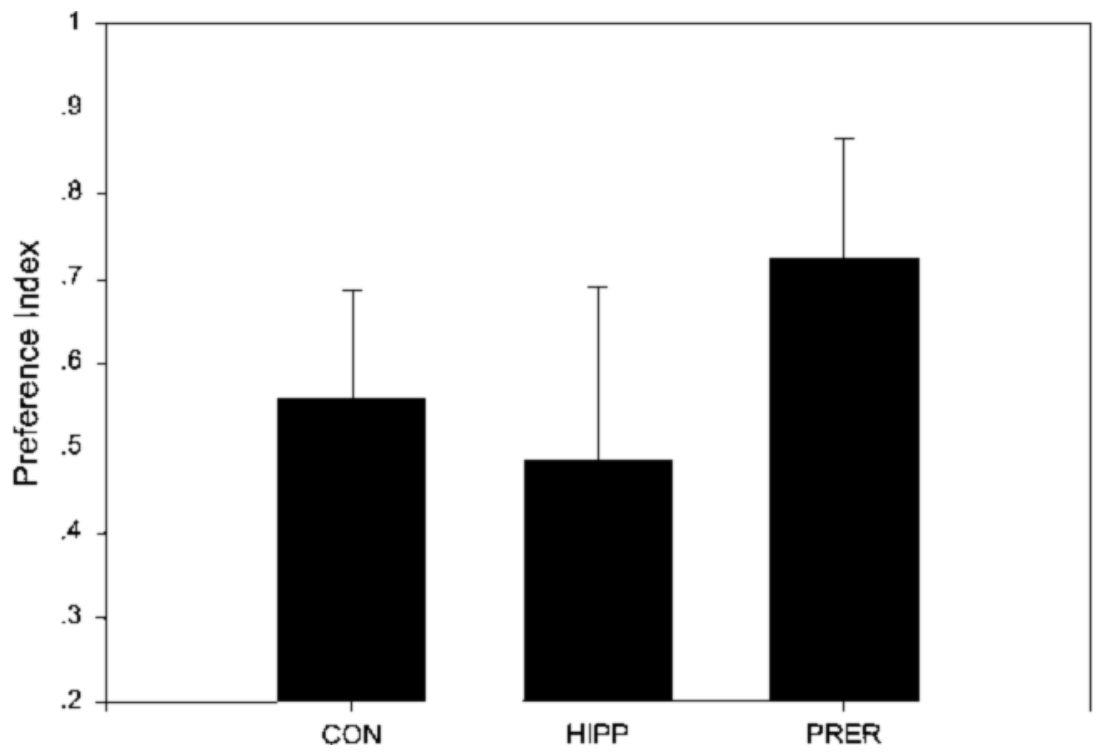

Figure 5. Mean preference index scores $(+S E M)$ on the postoperative test of Problem 1 for control subjects $(\mathrm{CON})$ and subjects with lesions to the perirhinal-entorhinal cortex (PRER) or the hippocampus (HIPP).

the probe trial is believed to yield a more sensitive indication of reward memory in this paradigm, where training is limited and retention is tested in just one trial.

The postoperative probe test performance on the recently learned olfactory discriminations(Problems 5 and 6 ) is illustrated in Figure 6. Group sizes used for these analyses were as follows: CON, $n=10$; PRER, $n=7$; and HIPP, $n=7$. A repeated measures ANOVA failed to detect a significant difference among groups across these problems $[F(2,21)=1.528, p=.240]$, with no signifi-

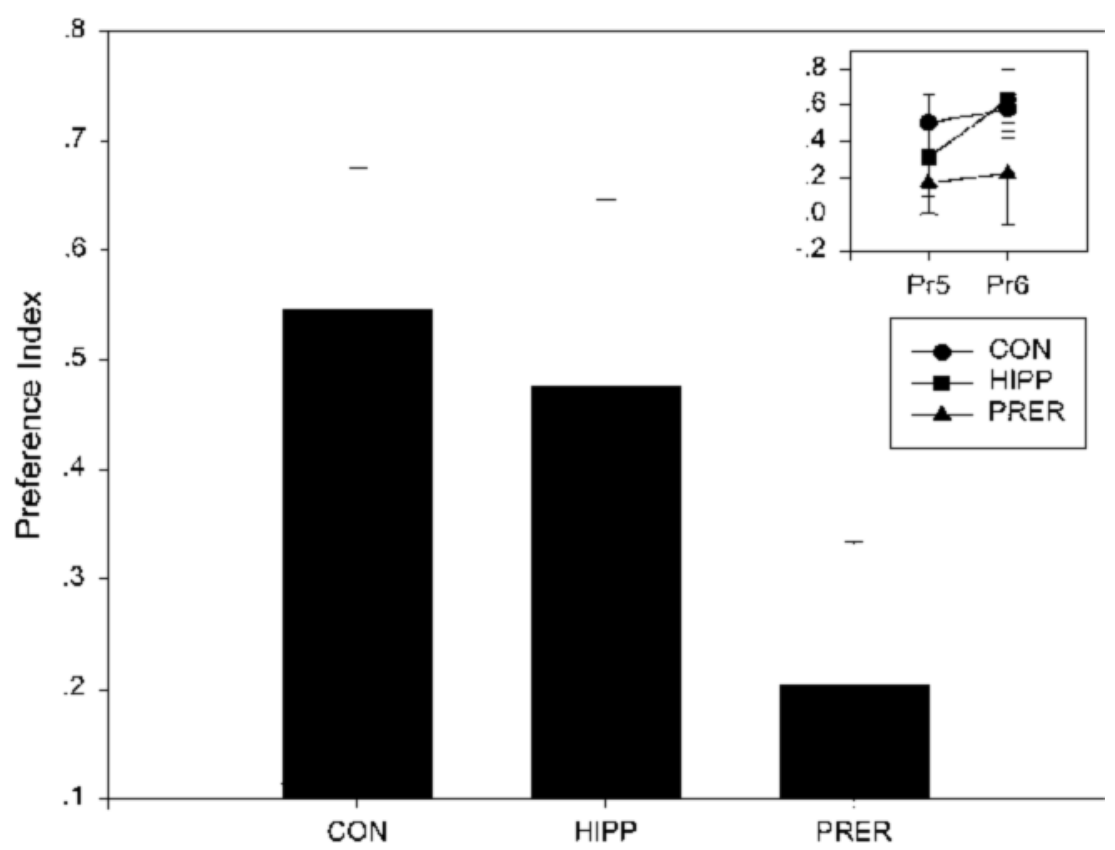

Figure 6. Mean preference index scores $(+S E M)$ for control subjects $(\mathrm{CON})$ and subjects with lesions to the perirhinal-entorhinal cortex (PRER) and the hippocampus (HIPP) on postoperative probe tests for Problems 5 and 6 (combined). Inset: Mean preference index scores $( \pm S E M)$ shown individually for Problems 5 (Pr5) and 6 (Pr6; i.e., the two recent problems). The dashed line (.0) indicates chance performance. 
cant difference noted between overall performance on Problem 5 or $6[F(1,21)=1.026, p=.323]$ and no interaction between problem and group $[F(2,21)=0.321, p=$ .729]. Despite the lack of statistical significance, the subjects in group PRER consistently performed at a level closer to chance than did the subjects in groups CON and HIPP (see Figure 6, inset). Moreover, the subjects in Group HIPP showed no memory decrement on the problem learned just 1-2 days before surgery (i.e., Problem 6), and their overall performance on both recent problems was quite comparable with group CON and numerically superior to group PRER.

Given the amount of damage to the hippocampus evident in PRER subjects, subsequent analyses were conducted to address any potential relationship between the amount of damage to the hippocampus and behavioral performance. Despite the incidental damage to the hippocampus in group PRER, this did not appear to be a significant factor in the diminished performance on recent problems. Group HIPP sustained significantly more damage to the hippocampus than did group PRER $[t(16)=$ $3.332, p=.004$ ], yet there was no significant relationship between the amount of damage to the hippocampus and recent memory performance for all groups combined (Pearson $r=-.047$ ) or for the two lesion groups alone (Pearson $r=.331$ ).

\section{Postoperative New Olfactory Learning}

The mean preference index scores following the 5-day retention intervals for the two olfactory discriminations learned after surgery are presented in Figure 7. A repeated measures ANOVA (group $\times$ problem) did not yield a significant group effect $[F(2,16)=2.837, p=$ $.088]$, and there were no effects of problem $[F(1,16)=$
$0.085, p=.774]$ and no evidence of a group $\times$ problem interaction $[F(2,16)=0.169, p=.846]$. The PRER subjects appeared to be the weakest numerically on these measures of long-term retention $(M=.46$ and .44$)$, whereas the subjects in groups CON $(M=.81$ and .80$)$ and HIPP $(M=.79$ and .93$)$ performed uniformly well across these two problems.

\section{Postoperative Water Maze Learning}

The mean latency to reach the submerged platform for each of the 12 training trials (4 trials per block) is presented in Figure 8A. A repeated measures ANOVA using the latency for each of the 12 training trials revealed a main effect of group $[F(2,17)=5.682, p=.013]$. There was a significant effect for trial number $[F(11,187)=$ $8.317, p<.001]$, indicating improvement across training trials (overall means: Trial $4=33.65 \mathrm{sec}$; Trial $8=22.00$ sec; Trial $12=11.05 \mathrm{sec}$ ). Separate ANOVAs showed group CON to be superior to group HIPP $[F(1,12)=$ $6.710, p=.024]$ and group PRER $[F(1,11)=9.618, p=$ $.01]$, whereas groups HIPP and PRER did not differ significantly from each other $[F(1,11)=2.306, p=.157]$. Performance on the probe trial measures taken immediately after the last training trial is shown in Figure 8B. A significant group effect was noted for the amount of time spent swimming in the target quadrant $(F(2,17)=8.217$, $p=.003$ ], and post hoc analyses showed group CON to be superior to group HIPP (Tukey, $p=.028$ ) and group PRER (Tukey, $p=.003$ ), but no difference between lesion groups (Tukey, $p=.498$ ). Analyses of swimming paths revealed a main effect for group in the number of annulus crossings (i.e., former platform location) during the probe trial $[F(2,17)=6.748, p=.007]$, with post hoc tests showing more platform crossings for group $\mathrm{CON}$

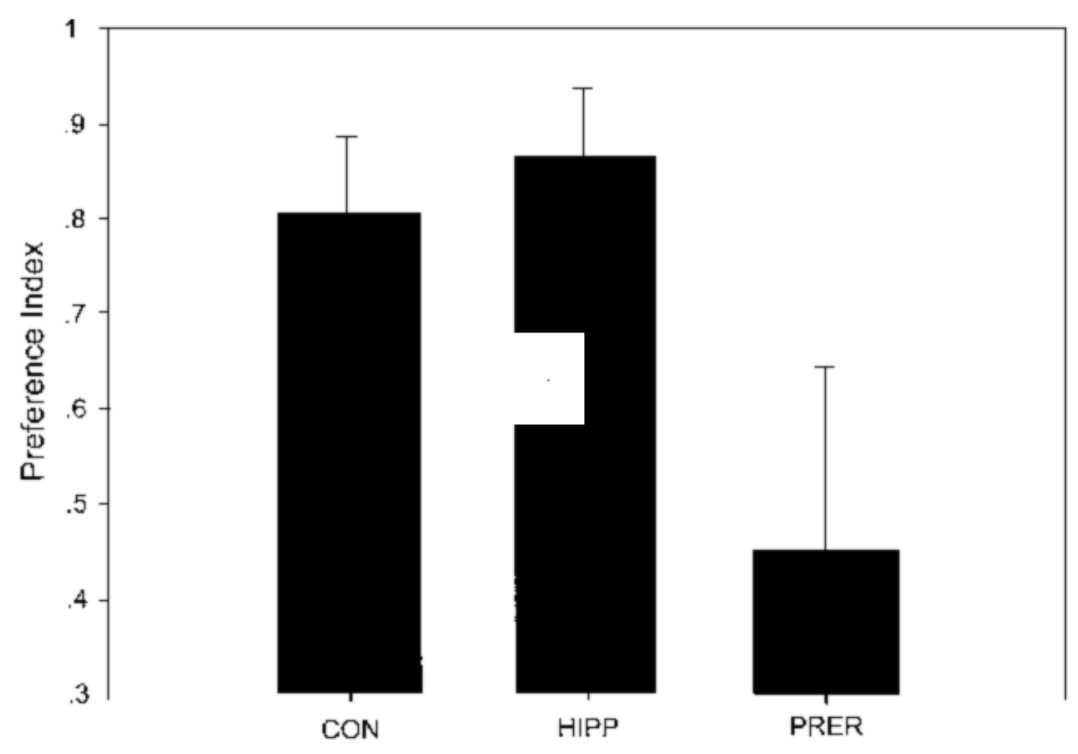

Figure 7. Mean preference index score $(+S E M)$ for control subjects $(\mathrm{CON})$ and subjects with lesions to the hippocampus (HIPP) and the perirhinal-entorhinal cortex (PRER) on the two 5-day retention problems learned postoperatively. 

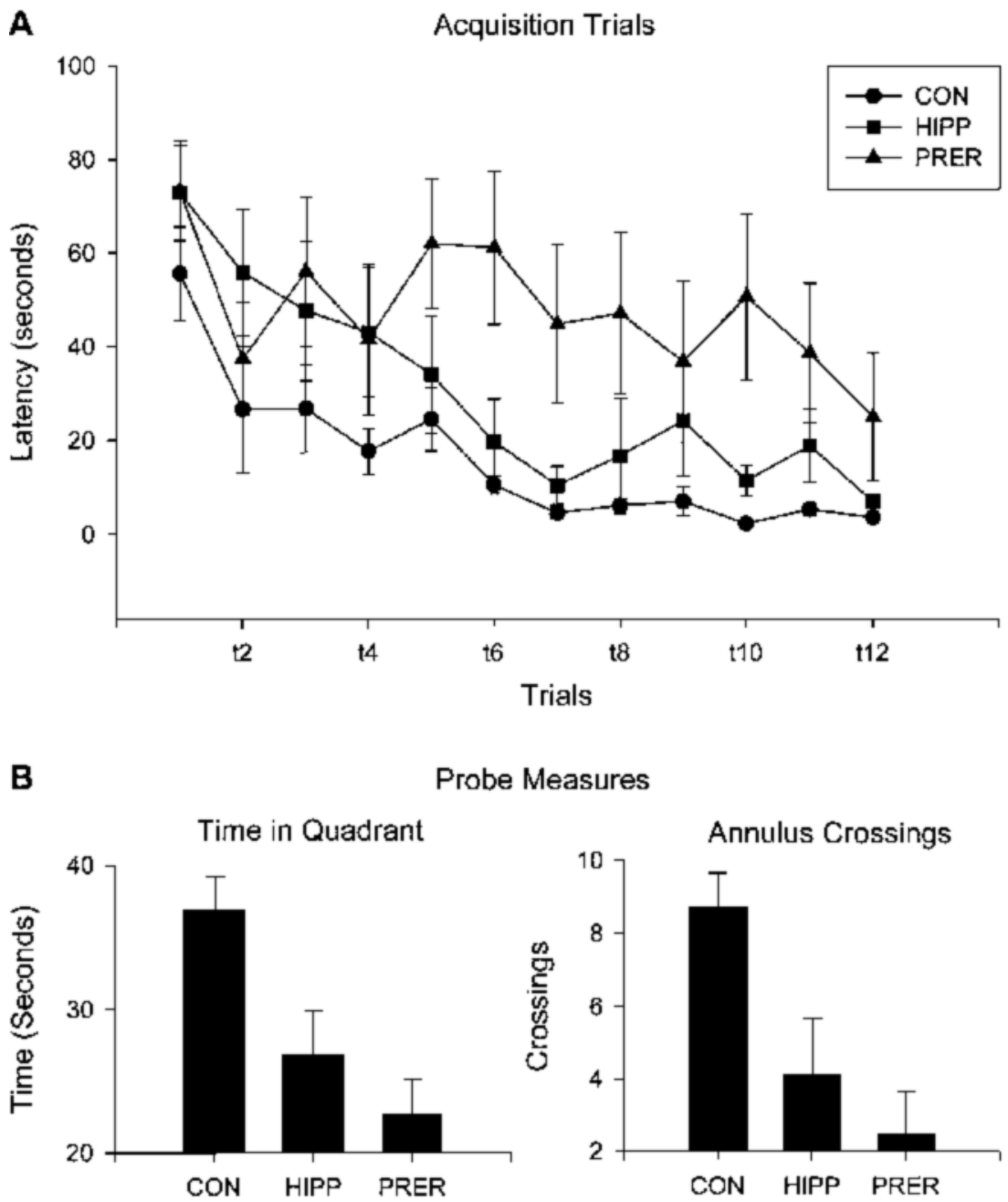

Figure 8. Results of water maze training and probe testing. (A) Mean latencies $( \pm S E M)$ to reach the submerged platform on each of 12 acquisition trials for control subjects (CON) and subjects with lesions to the hippocampus (HIPP) and the perirhinal-entorhinal cor tex (PRER). (B) Probe measures reflecting the mean time spent swimming in the target quadrant $(+S E M)$ and mean number of former platform crossings $(+S E M)$ during the 90 -sec probe trial.

than for group HIPP (Tukey, $p=.04$ ) and group PRER (Tukey, $p=.008$ ). Lesion groups did not differ from each other on this probe measure (Tukey, $p=.633$ ).

\section{DISCUSSION}

Considerable evidence from the human and animal literature has been used to support a role for the hippocampus in memory consolidation (Alvarez \& Squire, 1994; McClelland et al., 1995; Squire, 1992). The traditional view of hippocampal-dependent consolidation asserts that newly acquired information is reliant on the hippocampus for some time after a learning episode, during which time hippocampal circuitry facilitates the gradual establishment of long-term memories in a dis- tributed neocortical network (Alvarez \& Squire, 1994; Milner, 1989; Teyler \& DiScenna, 1986; Zola-Morgan \& Squire, 1990). Support for this contention is specifically evident in animal studies showing that information acquired within a 2-week period prior to hippocampal disruption is often poorly recalled, whereas material learned at times ranging from 4 to 8 weeks before the lesion is frequently spared (e.g., Anagnostaris et al., 1999; Kim et al., 1995; Kim \& Fanselow, 1992; Wiig et al., 1996; ZolaMorgan \& Squire, 1990).

The results of the present experiment do not undermine this theoretical notion but suggest that the hippocampus may not serve a time-limited role in memory formation for all types of information. A strict application of the consolidation perspective would argue here 
that the olfactory discriminations learned in the 3 weeks prior to surgery should have been more vulnerable to the effects of hippocampal damage than was the discrimination learned remotely in time (i.e., 4-7 weeks prior to surgery). More specifically, memory for the discrimination completed just days before surgery (i.e., Problem 6) was expected to have shown the most severe compromise following damage limited to the hippocampus. However, the results obtained here suggest that recognition memory for olfactory information may be readily established in long-term stores independent of a temporal period of hippocampal consolidation lasting on the order of 2-3 weeks (e.g., McClelland et al., 1995). This interpretation is consistent with results reported by Staubli et al. (1986), who found minimal impairment for olfactory information learned prior to hippocampal denervation, even if it was acquired less than $1 \mathrm{~h}$ prior to the lesion. Moreover, these results underscore the view that the hippocampus does not contribute to the retention and/or retrieval of nonrelational information (e.g., Myhrer, 1992) and is primarily involved in relational memory processes (see the discussion below; Bunsey \& Eichenbaum, 1996; Eichenbaum, Otto, \& Cohen, 1992, 1994; Eichenbaum et al., 1996).

The absence here of RA for recently acquired olfactory discriminations differs noticeably from recent reports showing a clear memory deficit for information acquired just prior to hippocampal damage (e.g., Anagnostaris et al., 1999; Kim \& Fanselow, 1992; Wiig et al., 1996; Zola-Morgan \& Squire, 1990). Reconciling these conflicting findings will necessitate further investigation into the methodological differences apparent in these studies, but two particular issues warrant consideration here. First, the marked difference in the learning tasks used across studies, and the sensory modalities emphasized, is an obvious and important procedural distinction. Second, the manner in which lesions are effected may significantly influence the pattern of results. The effect of these factors is likely to be synergistic; yet, each will be addressed in turn.

The different tasks used and the emphasis on different sensory modalities in these experiments may be of considerable importance in understanding the disparity in results. For example, the work of Kim and Fanselow (1992) and Anagnostaris et al. (1999) employed a fearconditioning paradigm to show a recent memory loss for contextual information. Inasmuch as contextual processing has reliably been shown to depend on the hippocampus in anterograde studies (Good \& Bannerman, 1997; Good \& Honey, 1991; Schmajuk, 1984), it is reasonable to expect amnesia for similar types of information in a retrograde paradigm (e.g., Anagnostaris et al., 1999).

Even the use of simple visual discriminations, although ostensibly not as complex as contextual learning tasks, may depend more on hippocampal processing than do simple olfactory stimuli. Wiig et al. (1996), using a visual discrimination paradigm, showed a temporally graded RA in rats with lesions affecting the hippocam- pus. In addition, they reported impairments in the longterm retention of postoperatively acquired discriminations, whereas the subjects in our study showed no longterm AA for olfactory discriminations. Therefore, the use of an olfactory rather than a visual paradigm may have contributed in some way to the spared memories for pre- and postoperatively learned discriminations. Interestingly, it has been reported that rats learn discriminations of an olfactory nature more easily than visual discriminations and more readily show positive transfer when trained with olfactory rather than visual cues (Nigrosh, Slotnick, \& Nevin, 1975). Moreover, Slotnick and Katz (1974) have argued that the rapid olfactory discrimination learning observed in rodents (and development of a learning set) likely reflects a biological preparedness for attention to olfactory stimuli. Staubli, Ivy, and Lynch (1984) and Staubli et al. (1986) underscored the ability of rodents to develop a learning set and readily acquire olfactory discriminations (e.g., within 20 trials) and reported their ability to retain this learning for at least 1 week (Staubli et al., 1986, see p. 439). Accordingly, it is tenable that information-processing demands in rodents may be quite different for those tasks emphasizing visual discrimination or contextual processing (e.g., Good \& Bannerman, 1997; Mumby, Pinel, Kornecook, Shen, \& Redila, 1995; Mumby et al., 1992; see also Cohen \& Eichenbaum, 1993), as compared with simple olfactory discrimination learning, thus markedly influencing the vulnerability to lesion-induced RA (e.g., Staubli et al., 1986). Such an argument reinforces the notion that the stimulus variables and/or the sensory modality emphasized may significantly influence species-specific learning (e.g., Slotnick \& Katz, 1974) and may ultimately impact interpretations of learning performance (Nigrosh et al., 1975).

The second issue that may significantly contribute to the disparity among results discussed here regards the nature of lesion methods. Excitotoxic lesions of the hippocampus yielded no RA here, whereas RA effects have generally been observed following electrolytic and aspiration lesions of the dorsal hippocampus (e.g., Anagnostaris et al., 1999; Kim \& Fanselow, 1992; Winocur, 1990) or damage to the fornix (Wiig et al., 1996). Given the disruptive nature of these lesions and/or the potential for damage to fibers of passage (Jarrard, 1989), it is arguable that the observed amnestic effects consequent to these techniques may not be specific to the hippocampus (Jarrard, 1993). Lesion techniques, such as fornix ablation and aspiration of the dorsal hippocampus, although disrupting hippocampal circuitry and yielding a pattern of RA (Wiig et al., 1996; Winocur, 1990), are likely to compromise portions of the PRER as well (Mitchell et al., 1982; Mizumori, Ward, \& Lavoie, 1992). Indeed, Vnek and Rothblat (1996) recently noted that long-term retention impairments for simple discriminations following aspiration lesions of the dorsal hippocampus may be due, in part, to degeneration of cells in the entorhinal cortex (see p. 2786). In addition, the recent emphasis on the 
rhinal cortex in object recognition memory (Levisohn \& Isacson, 1991; Meunier et al., 1993; Meunier et al., 1996; Myhrer, 1992; Suzuki et al., 1993; Vnek \& Rothblat, 1996; Zola-Morgan et al., 1989) underscores the importance of the brain tissue surrounding the rhinal sulcus in memory for visual discrimination material (Brown, 1996; Brown, Wilson, \& Riches, 1987; Murray, 1996). Recent work also suggests that RA for visual discrimination learning may be associated with damage to the entorhinal cortex and connections with the adjacent temporal neocortex, rather than to the hippocampus itself (Myhrer, 1992; Myhrer \& Johannesen, 1995). This argument does not necessarily undermine the involvement of the hippocampus in RA per se but suggests that ancillary damage or disruption to associated neural structures must be considered when assessing the neuroanatomy of RA.

To address the role of the broader hippocampal system in RA (i.e., including the PRER), the PRER group was included for comparison. The rhinal cortex was uniformly and extensively ablated in these subjects, coupled with incidental damage to portions of the hippocampus and the temporal neocortex. Given that the rhinal cortex and the associated temporal cortex are considered important for visual and olfactory stimulus recognition and retention (Bunsey \& Eichenbaum, 1995; Brown, 1996; Brown et al., 1987; Eichenbaum et al., 1996; Levisohn \& Isacson, 1991; Myhrer, 1992), it was anticipated that damage to this region of the rodent brain would result in an RA for all discriminations learned prior to surgery (e.g., Thornton et al., 1997). Although an extensive impairment for all preoperatively learned discriminations was not seen in these subjects, the qualitative profile across remote and recent discriminations is noteworthy. In particular, group PRER performed well on the remotely learned discrimination and was numerically superior here to groups $\mathrm{CON}$ and HIPP. In previous work, information acquired this long before hippocampal system lesions has been spared, relative to recently acquired information, hypothetically having been consolidated into a distributed neocortical store (Cho \& Kesner, 1996; Kim et al., 1995; Kim \& Fanselow, 1992; Wiig et al., 1996; Winocur, 1990; ZolaMorgan \& Squire, 1990). However, in the present experiment, the subjects received more extensive training on the remote discrimination (i.e., a maximum of 30 trials), and thus we cannot confidently attribute selective sparing on this problem to a time-dependent consolidation process (Nadel \& Moscovitch, 1997).

Indeed, the better preoperative choice performance on Problem 1 relative to Problems 5 and 6 (refer to Figure 4) may have been a function of the increased amount of training on this problem, and this training difference may have influenced the memory strength for Problem 1 at postoperative testing. However, despite the preoperative training differences between Problem 1 and Problems 5 and 6 , it is noteworthy that postoperative retention of Problem 1 was quite similar to the average postoperative retention scores on Problems 5 and 6 for those subjects in groups CON and HIPP (compare Figures 5 and 6). The same qualitative profile was not in evidence for group PRER. Accordingly, the impressive postoperative performance of group PRER on Problem 1 indicates that this extensive lesion did not disrupt motor skills (i.e., digging), procedural-level memories (i.e., foraging through cups placed in the home cage), or the ability to use odors to guide foraging behavior. Moreover, it suggests that any noticeable performance decline on other problems at testing may be attributed to mnemonic factors.

In contrast to the good performance on the remote problem, PRER subjects showed weaker postoperative memory for the recently learned problems. Although not reaching a level of statistical significance here, the preference index scores were close to chance on Problems 5 and 6, a finding that suggests a compromised availability of olfactory memories consequent to hippocampal system disruption. The fact that lesions restricted to the hippocampus proper did not yield such a performance pattern supports the current speculation that any performance decline observed in group PRER was likely due to disruption of the rhinal cortex or connections with the temporal neocortex (Myhrer, 1992; Myhrer \& Johannesen, 1995). More important, this pattern of results is in the same direction as the findings of Wiig et al. (1996), who reported a temporally graded RA for visual discriminations learned prior to electrolytic lesions of the rhinal cortex. In their study, memory for discriminations learned 1-2 weeks prior to surgery was impaired, whereas preserved memory was observed on a discrimination learned 6 weeks before the lesion.

The results of the anterograde experiments conducted postoperatively underscore the lack of hippocampus involvement in simple recognition memory. The long-term retention of novel olfactory discriminations was not impaired in groups HIPP or PRER, although PRER subjects again showed the weakest preference index scores on these problems. A previous study conducted in this lab (Flint et al., 1997) showed a large and significant PRER impairment under very similar training and testing conditions, thus supporting a growing literature implicating the rhinal cortex in recognition memory (Brown, 1996; Gaffan \& Parker, 1996; Meunier et al., 1993; Meunier et al., 1996; Murray, 1996). However, the absence of a statistically significant PRER impairment in long-term memory here agrees with a similar pattern of results reported by Thornton et al. (1997). Primates in their study showed a severe amnesia for visual discriminations learned prior to rhinal cortex surgery (i.e., including all discriminations learned up to 16 weeks presurgery), yet were spared in postoperative visual discrimination learning and retention. On the basis of this unique pattern of results, they speculated that discriminations acquired while the rhinal cortex was intact (i.e., prior to surgery) would ultimately depend on this area of the cortex for later retention, whereas new postoperative discriminations learned in the absence of the rhinal cortex could be supported by an alternative memory system. The statistical results reported here offer support for this general framework, but 
the tendency toward low retention scores for group PRER here necessitates caution, and further exploration, to better address this interpretation.

The impairment seen in the water maze here confirms the behavioral effect of the HIPP and PRER lesions and adds to an extensive literature emphasizing the involvement of the hippocampus and the rhinal cortex in spatial processing (Bannerman, Good, Butcher, Ramsay, \& Morris, 1995; Duva et al., 1997; Eichenbaum et al., 1992; Jarrard, 1993; Morris, Anderson, Lynch, \& Baudry, 1986; Morris, Garrud, Rawlins, \& O'Keefe, 1982; Nagahara et al., 1995). Furthermore, we can conclude that the lack of RA following specific HIPP lesions was not due to inadequate lesions. Histology showed the lesions to be extensive, and the water maze impairment nicely dissociates the involvement of these structures in simple recognition memory and more complex relational tasks, such as maze learning.

\section{CONCLUSIONS}

The overall findings in the present experiment suggest that selective damage to the hippocampus does not significantly compromise memory for olfactory cues acquired just prior to surgery. In addition, damage to the hippocampus did not impair postoperative retention of olfactory learning. The absence of RA for olfactory cues in HIPP subjects argues against a consolidation role for this structure, at least with respect to olfactory information. The implication here is that RA following damage to the hippocampus may be modality and/or task specific. Accordingly, the hippocampus may be involved in memory consolidation, but only for certain types of information, presumably the same types shown to be affected in anterograde studies (e.g., visual, contextual, and spatial-relational; Anagnostaris et al., 1999; Bolhuis et al., 1994; Kim \& Fanselow, 1992; Wiig et al., 1996; Winocur, 1990). The marked impairment observed for group HIPP in the water maze is consistent with expectations based on the well-established role of the hippocampus in spatial memory (Jarrard, 1993; Morris et al., 1986; Morris et al., 1982; O'Keefe \& Nadel, 1978) and supports the functional distinction between tasks of a nonrelational and relational nature with regard to hippocampal processing (e.g., discrimination learning vs. spatial maze learning; Cohen \& Eichenbaum, 1993; Duva et al., 1997; Eichenbaum et al., 1992).

Subjects with substantial damage to the rhinal cortex were impaired as anticipated in water maze learning (Nagahara et al., 1995) but did not show a pattern of significant memory loss in the retrograde olfactory task. Despite this lack of statistical significance, the numerical weakness evident in the performance of group PRER on problems learned just prior to surgery is qualitatively similar to the results of other studies (e.g., Cho et al., 1993; Cho \& Kesner, 1996; Wiig et al., 1996) and merits further investigation. Collectively, the results reported here and elsewhere (Cho et al., 1993; Eacott, 1998; Myhrer \& Wangen, 1996; Thornton et al., 1997; Wiig et al.,
1996) underscore the importance of the rhinal cortex in retrograde memory and also suggest that it serves a multimodal role in memory processes. Indeed, electrophysiological characterizations of the rhinal cortex suggest that cells in this region respond selectively to visual and olfactory cues (Brown, 1996; Brown et al., 1987; Eichenbaum et al., 1996), and lesion studies confirm the role of this brain region in recognition memory for visual and olfactory tasks (e.g., Bunsey \& Eichenbaum, 1993; Gaffan \& Parker, 1996; Otto \& Eichenbaum, 1992; Staubli et al., 1984).

The present findings represent an initial step in a functional neuroanatomical approach to RA modeling with rodents, using an olfactory paradigm. However, numerous questions remain. Given the memory sparing evident in subjects with specific damage to the hippocampus and the indication of compromised recent memory performance following rhinal cortex lesions, the role of the rhinal cortex in RA is an area of considerable interest for further inquiry (e.g., Cho \& Kesner, 1996; Thornton et al., 1997). Previous studies have shown RA following lesions to the hippocampus (Kim et al., 1995; Kim \& Fanselow, 1992), the perirhinal cortex (Myhrer \& Wangen, 1996; Wiig et al., 1996), or the entorhinal cortex (Cho et al., 1993; Cho \& Kesner, 1996), but numerous methodological differences across studies (e.g., lesion technique, training paradigm) need to be more completely addressed before a unified understanding can be developed regarding the role served by the hippocampus and the rhinal cortex in information acquisition and retention.

\section{REFERENCES}

Alvarez, P., \& Squire, L. R. (1994). Memory consolidation and the medial temporal lobe: A simple network model. Proceedings of the National Academy of Sciences, 93, 13547-13551.

Alvarez, P., Zola-Morgan, S., \& Squire, L. R. (1995). Damage limited to the hippocampal region produces long-lasting memory impairment in monkeys. Journal of Neuroscience, 15, 3796-3807.

Anagnostaris, S. G., Maren, S., \& Fanselow, M. S. (1999). Temporally graded retrograde amnesia of contextual fear after hippocampal damage in rats: Within-subjects examination. Journal of Neuroscience, 19, 1106-1114.

Bannerman, D. M., Good, M. A., Butcher, S. P., Ramsay, M., \& Morris, R. G. M. (1995). Distinct components of spatial learning revealed by prior training and NMDA receptor blockade. Nature, $\mathbf{3 7 8}$, 182-186.

Bolhuis, J. J., Stewart, C. A., \& Forrest, E. M. (1994). Retrograde amnesia and memory reactivation in rats with ibotenate lesions to the hippocampus or subiculum. Quarterly Journal of Experimental Psychology, 47B, 129-150.

Bouffard, J. P., \& Jarrard, L. E. (1988). Acquisition of a complex place task in rats with selective ibotenate lesions of hippocampal formation: Combined lesions of subiculum and entorhinal cortex versus hippocampus. Behavioral Neuroscience, 102, 828-834.

Brown, M. W. (1996). Neuronal responses and recognition memory. Seminars in the Neurosciences, 8, 23-32.

Brown, M. W., Wilson, F. A. W., \& Riches, I. P. (1987). Neuronal evidence that inferomedial temporal cortex is more important than hippocampus in certain processes underlying recognition memory. Brain Research, 409, 158-162.

Bunsey, M., \& Eichenbaum, H. (1993). Paired associate learning in rats: Critical involvement of the parahippocampal region. Behavioral Neuroscience, 107, 740-747.

Bunsey, M., \& Eichenbaum, H. (1995). Selective damage to the hip- 
pocampal region blocks long-term retention of a natural and nonspatial stimulus-stimulus association. Hippocampus, 5, 546-556.

Bunsey, M., \& Eichenbaum, H. (1996). Conservation of hippocampal memory function in rats and humans. Nature, 379, 255-257.

Cho, Y. H., Beracochea, D., \& JAFFard, R. (1993). Extended temporal gradient for retrograde and anterograde amnesia produced by ibotenate entorhinal cortex lesions in mice. Journal of Neuroscience, 13, 1759-1766.

Cho, Y. H., \& KeSNER, R. P. (1996). Involvement of entorhinal cortex or parietal cortex in long-term spatial discrimination memory in rats: Retrograde amnesia. Behavioral Neuroscience, 110, 436-442.

Cohen, N. J., \& Eichenbaum, H. (1993). Memory, amnesia and the hippocampal system. Cambridge, MA: MIT Press.

CoRKIN, S. (1984). Lasting consequences of bilateral medial temporal lobectomy: Clinical course and experimental findings in H.M. Seminars in Neurobiology, 4, 249-259.

Corkin, S., Amaral, D. G., Gonzalez, R. G., Johnson, K. A., \& Hyman, B. T. (1997). H.M.'s medial temporal lobe lesion: Findings from magnetic resonance imaging. Journal of Neuroscience, 17, 3964-3979.

Duva, C. A., Floresco, S. B., Wunderlich, G. R, Lao, T. L., Pinel, J. P. J., \& Phillips, A. G. (1997). Disruption of spatial but not objectrecognition memory by neurotoxic lesions of the dorsal hippocampus in rats. Behavioral Neuroscience, 111, 1184-1196.

EAсотт, M. J. (1998). Acquisition and retention of visual discrimination learning after ablation of perirhinal cortex in the rat. Psychobiology, 26, 36-41.

Eichenbaum, H. (1997). How does the brain organize memories? Science, 277, 330-332.

Eichenbaum, H., Otto, T., \& Cohen, N. J. (1992). The hippocampus: What does it do? Behavioral \& Neural Biology, 57, 2-36.

Eichenbaum, H., Otto, T., \& Cohen, N. J. (1994). Two functional components of the hippocampal system. Behavioral \& Brain Sciences, 17, 449-517.

Eichenbaum, H., Schoenbaum, G., Young, B., \& Bunsey, M. (1996). Functional organization of the hippocampal memory system. Proceedings of the National Academy of Sciences, 93, 13500-13507.

Flint, R. W., KaUt, K. P., \& Bunsey, M. (1997). The hippocampus and perirhinal-entorhinal cortices in simple olfactory task retention. Society for Neuroscience Abstracts, 27, 281.

GAFFAN, D., \& PARKER, A. (1996). Interaction of perirhinal cortex with the fornix-fimbria: Memory for objects and "object-in-place" memory. Journal of Neuroscience, 16, 5864-5869.

Good, M., \& Bannerman, D. (1997). Differential effects of ibotenic acid lesions of the hippocampus and blockade of $N$-methyl-D-aspartate receptor-dependent long-term potentiation on contextual processing in rats. Behavioral Neuroscience, 111, 1171-1183.

Good, M., \& Honey, R. C. (1991). Conditioning and contextual retrieval in hippocampal rats. Behavioral Neuroscience, 105, 499-509.

Holscher, C., \& Schmidt, W. J. (1994). Quinolinic acid lesions of the rat entorhinal cortex pars medialis produces selective amnesia in allocentric working memory (WM), but not in egocentric WM. Behavioural Brain Research, 63, 187-194.

JARRARD, L. E. (1989). On the use of ibotenic acid to lesion selectively different components of the hippocampal system. Journal of Neuroscience Methods, 29, 251-259.

JARRARD, L. E. (1993). On the role of the hippocampus in learning and memory in the rat. Behavioral \& Neural Biology, 60, 9-26.

Kim, J. J., Clark, R. E., \& Thompson, R. F. (1995). Hippocampectomy impairs memory of recently, but not remotely, acquired trace eyeblink conditioned responses. Behavioral Neuroscience, 109, 195-203.

KIM, J. J., \& FANSELOW, M. S. (1992). Modality-specific retrograde amnesia of fear. Science, 256, 675-677.

Kraemer, P. J., Brown, R. W., Baldwin, S. A., \& Scheff, S. W. (1996). Validation of a single-day Morris water maze procedure used to assess cognitive deficits associated with brain damage. Brain Research Bulletin, 39, 17-22.

LEVISOHN, L. F., \& ISACSON, O. (1991). Excitotoxic lesions of the rat entorhinal cortex: Effects of selective neuronal damage on acquisition and retention of a non-spatial reference memory task. Brain Research, 564, 230-244.

LIU, P., \& BILKEy, D. K. (1998). Excitotoxic lesions centered on perirhi- nal cortex produce delay-dependent deficits in a test of spatial memory. Behavioral Neuroscience, 112, 512-524.

McClelland, J. L., McNaughton, B. L., \& O’Reilly, R. C. (1995). Why there are complementary learning systems in the hippocampus and neocortex: Insights from successes and failures of connectionist models of learning and memory. Psychological Review, 102, 419457.

Meunier, M., Bachevalier,J., Mishin, M., \& Murray, E. A. (1993). Effects on visual recognition of combined and separate ablations of the entorhinal and perirhinal cortex in rhesus monkeys. Journal of Neuroscience, 13, 5418-5432.

Meunier, M., Hadfield, W., Bachevalier, J., \& Murray, E. A. (1996). Effects of rhinal cortex lesions combined with hippocampectomy on visual recognition memory in rhesus monkeys. Journal of Neurophysiology, 75, 1190-1205.

MiLnER, P. M. (1989). A cell assembly theory of hippocampal amnesia. Neuropsychologia, 27, 23-30.

Mitchell, S. J., Rawlins, J. N. P., Steward, O., \& Olton, D. S. (1982). Medial septal area lesions disrupt theta rhythm and cholinergic staining in medial entorhinal cortex and produce impaired radial arm maze behavior in rats. Journal of Neuroscience, 2, 292-302.

Mizumori, S. J. Y., Ward, K. E., \& Lavoie, A. M. (1992). Medial septal modulation of entorhinal single unit activity in anesthetized and freely moving rats. Brain Research, 570, 188-197.

Morris, R. G. M., ANderson, E., Lynch, G. S., \& Baudry, M. (1986). Selective impairment of learning and blockade of long-term potentiation by an $N$-methyl-D-aspartate receptor antagonist, AP5. Nature, 319, 774-776.

Morris, R. G. M., Garrud, P., Rawlins, J. N. P., \& O'Keefe, J. (1982). Place navigation impaired in rats with hippocampal lesions. Nature, 297, 681-683.

Mumby, D. G., Pinel, J. P. J., Konnecook, T. J., Shen, M. J., \& Redila, V. A. (1995). Memory deficits following lesions of hippocampus or amygdala in rat: Assessment by an object-memory test battery. Psychobiology, 23, 26-36.

Mumby, D. G., Wood, E. R., \& Pinel, J. P. J. (1992). Object-recognition memory is only mildly impaired in rats with lesions of the hippocampus and amygdala. Psychobiology, 20, 18-27.

Murray, E. A. (1996). What have ablation studies told us about the neural substrates of stimulus memory. Seminars in the Neurosciences, 8, 13-22.

Murray, E. A., Gaffan, D., \& Mishrin, M. (1993). Neural substrates of visual stimulus-stimulus association in rhesus monkeys. Journal of Neuroscience, 13, 4549-4561.

MyHrer, T. (1992). Selective lesions in the temporal-hippocampal region of the rat: Effects on acquisition and retention of a visual discrimination task. Behavioral \& Neural Biology, 58, 8-15.

Myhrer, T., \& Johannesen, T. S. (1995). Learning and retention of a visual discrimination task in rats with various combinations of lesions in the temporal-hippocampal region. Brain Research Bulletin, 36, 499-503.

Myhrer, T., \& WANGEN, K. (1996). Marked retrograde and anterograde amnesia of a visual discrimination task in rats with selective lesions of the perirhinal cortex. Neurobiology of Learning \& Memory, 65, 244-252.

NADEL, L., \& Moscovitch, M. (1997). Memory consolidation, retrograde amnesia and the hippocampal complex. Current Opinion in Neurobiology, 7, 217-227.

Nagahara, A. H., Otto, T., \& Gallagher, M. (1995). Entorhinal lesions impair performance in two versions of place learning in the Morris water maze. Behavioral Neuroscience, 109, 3-9.

Nigrosh, B. J., SLot Nick, B. M., \& Nevin, J. A. (1975). Olfactory discrimination, reversal learning, and stimulus control in rats. Journal of Comparative \& Physiological Psychology, 89, 285-294.

O'KeEFE, J., \& NADEL, L. (1978). The hippocampus as a cognitive map. Oxford: Oxford University Press.

Otтo, T., \& Eichenbaum, H. (1992). Complementary roles of orbital prefrontal cortex and the perirhinal-entorhinal cortices in an odorguided non-matching to sample task. Behavioral Neuroscience, 106, 763-776.

PAXINos, G., \& WATSON, C. (1997). The rat brain in stereotaxic coordinates. San Diego: Academic Press. 
Pellegrino, L. J., Pellegrino, A. S., \& Cushman, A. J. (1979). A stereotaxic atlas of the rat brain (2nd ed.). New York: Plenum.

ReEd, J. M., \& Squire, L. R. (1998). Retrograde amnesia for facts and events: Findings from four new cases. Journal of Neuroscience, 18, 3943-3954.

Rempel-Clower, N. L., Zola, S. M., Squire, L. R., \& Amaral, D. G. (1996). Three cases of enduring memory impairment after bilateral damage limited to the hippocampal formation. Journal of Neuroscience, 16, 5233-5255.

Salmon, D. P., Zola-Morgan, S., \& SQuire, L. R. (1987). Retrograde amnesia following combined hippocampus-amygdala lesions in monkeys. Psychobiology, 15, 37-47.

SchmajuK, N. (1984). Psychological theories of hippocampal function. Physiological Psychology, 12, 166-183.

Scoville, W. B., \& Milner, B. (1957). Loss of recent memory after bilateral hippocampal lesions. Journal of Neurology, Neurosurgery, \& Psychiatry, 20, 11-21.

Slotnick, B. M., \& Katz, H. M. (1974). Olfactory learning-set formation in rats. Science, $\mathbf{1 8 5}, 796-798$.

SQUIRE, L. R. (1992). Memory and the hippocampus: A synthesis of the findings with rats, humans, and monkeys. Psychological Review, 99, 195-231.

Staubli, U., Fraser, D., Kessler, M., \& Lynch, G. (1986). Studies on retrograde and anterograde amnesia of olfactory memory after denervation of the hippocampus by entorhinal cortex lesions. Behavioral \& Neural Biology, 46, 432-444.

Staubli, U., Ivy, G., \& Lynch, G. (1984). Hippocampal denervation causes rapid forgetting of olfactory information in rats. Proceedings of the National Academy of Science, 81, 5885-5887.

Suzuki, W. A., Zola-Morgan, S., Squire, L. R., \& Amaral, D. G. (1993). Lesions of the perirhinal and parahippocampal cortices in the monkey produce long-lasting memory impairment in the visual and tactual modalities. Journal of Neuroscience, 13, 2430-2451.

Teyler, T. J., \& DiScenna, P. (1986). The hippocampal memory indexing theory. Behavioral Neuroscience, 100, 147-154.
Thornton, J. A., Rothblat, L. A., \& Murray, E. A. (1997). Rhinal cortex removal produces amnesia for preoperatively learned discrimination problems but fails to disrupt postoperative acquisition and retention in rhesus monkeys. Journal of Neuroscience, 17, 85368549.

VNek, N., \& Rothblat, L. A. (1996). The hippocampus and long-term object memory in the rat. Journal of Neuroscience, 16, 2780-2787.

Warrington, E. K., \& McCARThy, R. A. (1988). The fractionation of retrograde amnesia. Brain Cognition, 7, 184-200.

WiIG, K. A., CoOper, L. N., \& BEAR, M. F. (1996). Temporally graded retrograde amnesia following separate and combined lesions of the perirhinal cortex and fornix in the rat. Learning \& Memory, 3, 313-325.

WinOCUR, G. (1990). Anterograde and retrograde amnesia in rats with dorsal hippocampal or dorsomedial thalamic lesions. Behavioral Brain Research, 38, 145-154.

Zola-Morgan, S., \& Squire, L. (1985). Medial temporal lesions in monkeys impair memory on a variety of tasks sensitive to human amnesia. Behavioral Neuroscience, 9, 22-34.

Zola-Morgan,S., \& SQUire, L. (1990). The primate hippocampal formation: evidence for a time-limited role in memory storage. Science, 250, 288-290.

Zola-Morgan,S., SQuire, L. R., \& Amaral, D. G. (1986). Human amnesia and the medial temporal region: Enduring memory impairments following a bilateral lesion limited to field CA1 of the hippocampus. Journal of Neuroscience, 6, 2950-2967.

Zola-Morgan, S., Souire, L. R., Amaral, D. G., \& Suzuki, W. A. (1989). Lesions of perirhinal and parahippocampal cortex that spare the amygdala and hippocampal formation produce severe memory impairment. Journal of Neuroscience, 9, 4355-4370.

Zola-Morgan, S. M., SQuire, L. R., \& Mishrin, M. (1982). The neuroanatomy of amnesia: Amygdala-hippocampus versus temporal stem. Science, 218, 1337-1339.

(Manuscript received September 21, 2000; revision accepted for publication July 6, 2001.) 